\title{
Environmental Impact of Beach Nourishment: A Case Study of the Rio San Pedro Beach (SW Spain)
}

\author{
A. Herrera ${ }^{*}, 1$, G. Gomez-Pina ${ }^{2}$, L. Fages ${ }^{2}$, A. De La Casa ${ }^{2}$ and J.J. Muñoz-Perez ${ }^{3}$ \\ ${ }^{1}$ Anfitrix, S.L. Avda. Marconi, 37- 3, 11001 Cadiz, Spain \\ ${ }^{2}$ Coastal Department, Ministry of Environment, Marianista Cubillo n.7, 11071 Cadiz, Spain \\ ${ }^{3}$ Applied Physics Department, University of Cadiz, CASEM, 11500 Puerto Real, Spain
}

\begin{abstract}
The beaches on the left bank of Rio San Pedro (SW Spain) are in a regressive state because of the human activities of recent decades. With the objective of minimizing the effects of the erosion, the Spanish Coastal Department (Ministry of the Environment) decided that the most suitable solution was to provide sand nourishment. Previously, an environmental impact study (EIS) was carried out on these beaches, and an environmental monitoring campaign was also completed during that nourishment. A new methodology to perform this kind of studies is proposed in the present report. Moreover, a form is proposed for establishing the degree of observance of the EIS. Additionally, discrepancies in opinions on the alleged environmental impact of the sand nourishment on the Uca tangeri (European Fiddler crab), a representative but not protected species that lives in the area of research, led to the development of a complementary study. Therefore, observations, experimentations and calculations were carried out on individuals of this species of crab. It was concluded that there was no significant impact on this crab's population. With respect to the impact of the sand nourishment project, the overall impact was negative but negligible during the nourishment phase. Once the project was finished, the total environmental impact was also negligible but positive overall.
\end{abstract}

\section{INTRODUCTION}

Beach nourishment is one of several soft structural stabilization techniques that also include beach bulldozing or scraping, dune creation, restoration and reshaping. Most countries have shifted from hard structure approaches to policies that favor soft structures [1]. Furthermore, some states, like New Jersey, North Carolina, South Carolina and Maine, have outlawed shoreline armoring [2]. Beach replenishment can be defined as a process of mechanically or hydraulically placing sand on an eroding shore to restore or form and subsequently maintain an adequate protective or recreational beach [3].

Artificial beach nourishment is increasingly being recognized as an effective way to combat coastal erosion problems [4]. Compared with other methods to protect the coastline, beach replenishment is not only more flexible but also offers potential benefits including safeguarding the environment and improving recreational facilities. However, transporting the sand for this technique may pose a threat to the environment.

Scraping consists of redistributing sand on the beach from the intertidal or submerged zone to the upper beach by mechanical means (bulldozing). This method is useful to provide a wider recreational beach and to protect shoreline structures. Nevertheless, some authors $[5,6]$ indicate that

*Address correspondence to this author at the Anfitrix, S.L. Avda. Marconi, 37- 3, 11001 Cadiz, Spain; Tel: +34 9562008 44;

E-mail: info@anfitrix.com this method can have negative effects on the resident biological community.

In order to gain a better understanding of the potential environmental impact of beach nourishment or scraping, it is essential to have an accurate description of the environmental conditions at the borrow and replenishment sites prior to initiating the project [7]. By supplementing this information with data collected during and after the replenishment activities, a detailed comparison can be made. This approach helps to ensure that beach nourishment is performed in an environmentally acceptable manner [8].

The aim of this paper is to describe a methodology to assess the environmental impact of beach nourishment. We apply this proposed methodology to a particular case (Rio San Pedro, SW Spain), that is easily generalized to other sites with similar characteristics; then we discuss the problems that arose during this sand nourishment and the solutions.

\section{THE STUDY AREA}

The area of study is located in Puerto Real, which is situated inside the Bay of Cadiz in the southwestern end of the Iberian Peninsula (about 36 $31^{\prime} \mathrm{N}$ and $6^{\circ} 13^{\prime} \mathrm{W}$ ) where low coastal areas with sand bars and tidal marshes dominate (Fig. 1).

The San Pedro River mouth is formed by a spit (as a consequence of the littoral dynamics or waves and the movements of the tidal currents) called the Punta de los Sabonenses. Both the tidal marshes and the pine wood are 

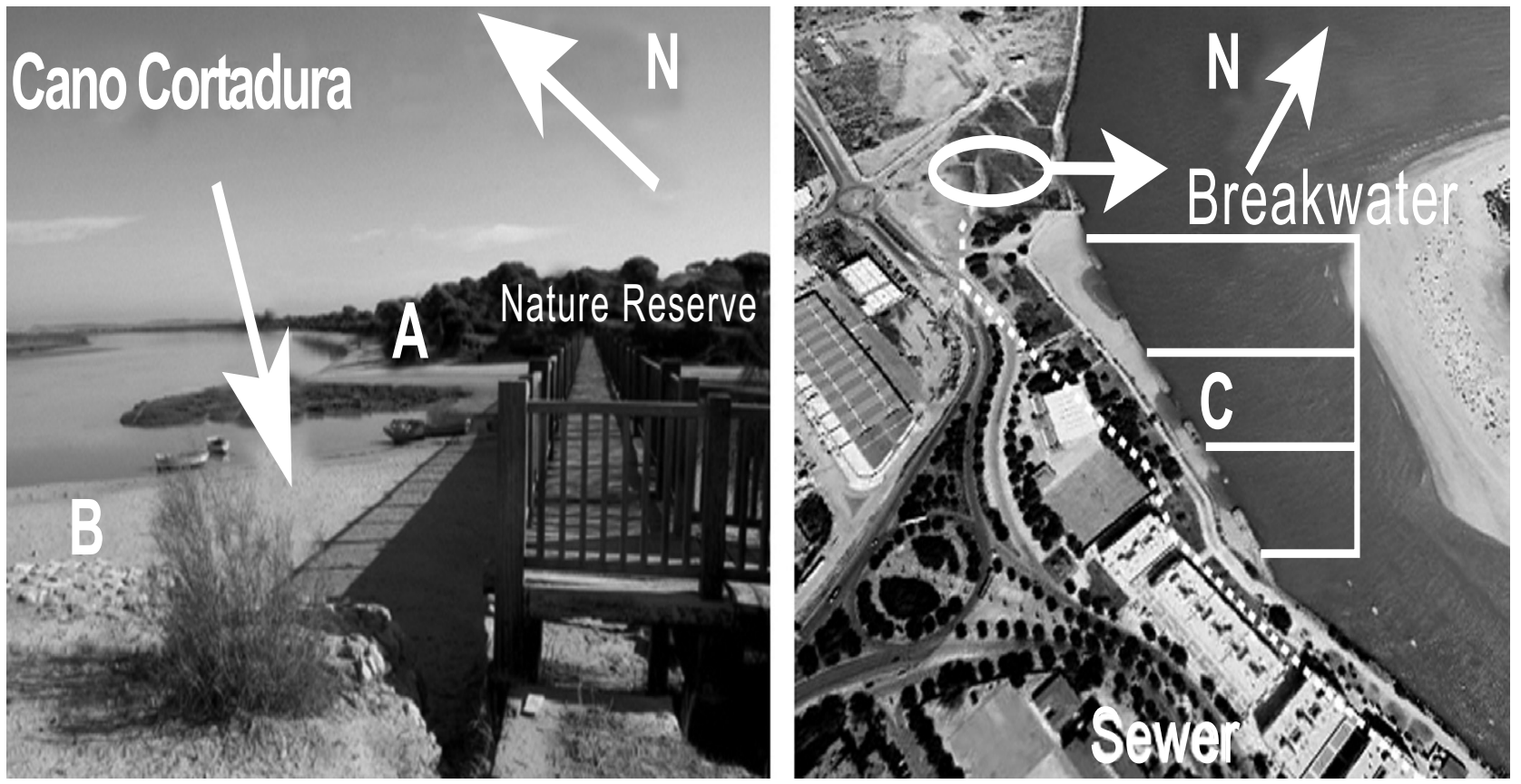

Fig. (1). The location of Cadiz in the Iberian Peninsula. The nourished beaches on the San Pedro River (A and B are upwards and downwards Caño de Cortadura; $\mathbf{C}$ is a pocket beach behind the detached breakwaters).

called La Algaida (in Arabian it means "the wood" and they are part of the Cadiz Bay Nature Reserve.

This area is affected by semidiurnal tides that have a maximal tidal range less than $4 \mathrm{~m}$ [9]. The beach is formed by fine sand $\left(D_{50}=0.25 \mathrm{~mm}\right)$ and $10 \%$ of it is bioclastic material. Its bathymetry is characterized by a deep central area flanked by a wide, mildly sloping plain on the right bank. The tidal current is maximum during 3hours. Then, the current diminishes gradually until it becomes a minimum at

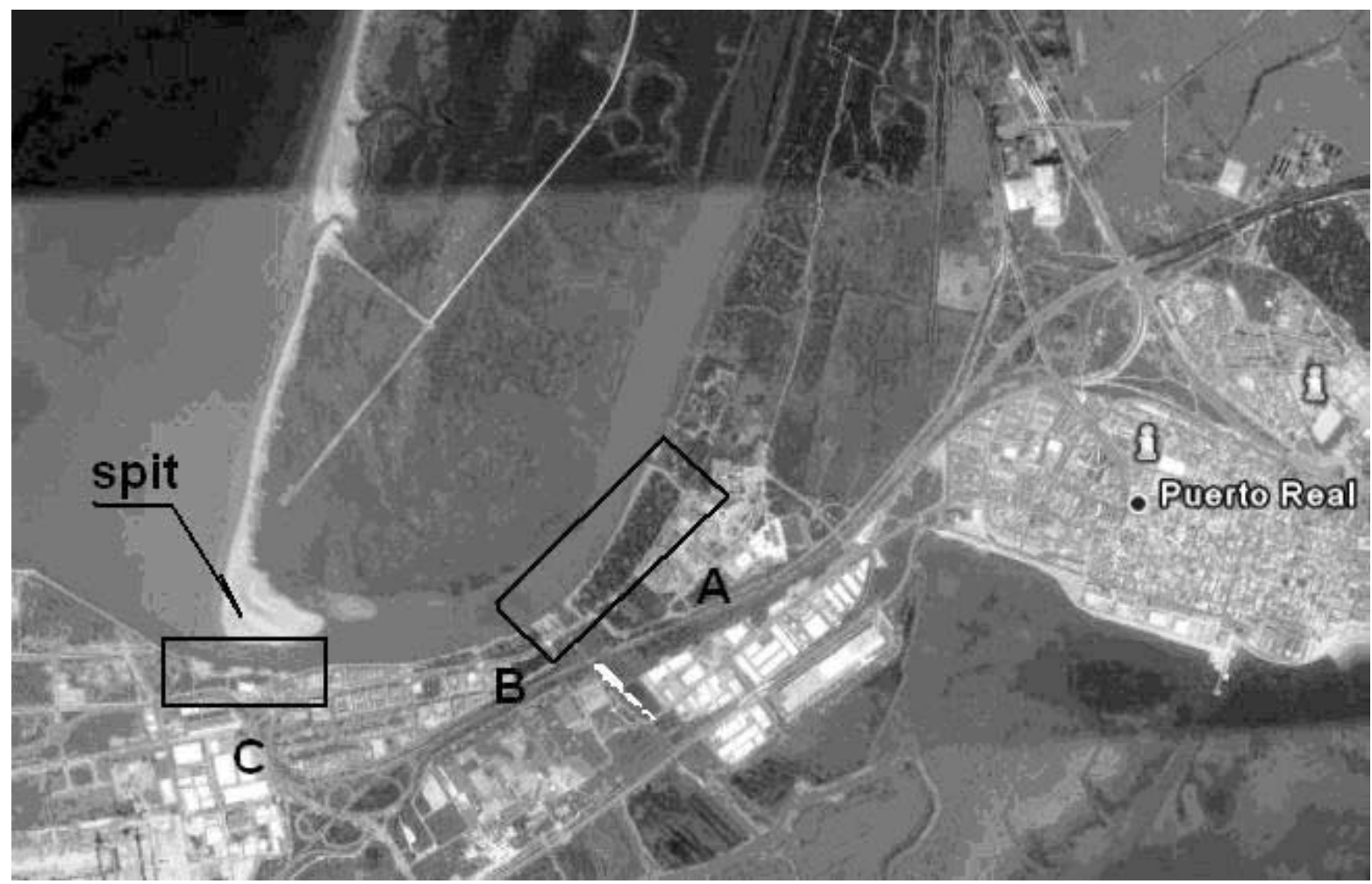

Fig. (2). An aerial photograph showing where the arrow-shaped beach is located. The nourished areas are framed in rectangles. 
flood tide level; the current increases again and becomes a minimum once more at the low water tide. Moreover, the water stream is faster on the top surface than on the bottom and the center, and it is faster along the left bank than on the right shore. Note that the littoral dynamics have created a spit (an arrow-shaped beach) in the outside area (Fig. 2).

Urban development activities carried out in recent decades have modified the state of the beach, both diminishing the flow of the rising and falling tidal prism of the river [10] and causing a decrease in the outfall section, which is gradually invaded by the sediments of the western adjacent beach. More specifically, the coastal dynamics of the San Pedro River (see Fig. 1) have been affected in recent decades by marsh filling and the construction of $\mathrm{La}$ Cabezuela dock on the left bank mouth. These construction activities as well as the rubble-mound seawalls built on some parts of the bank could have been the cause for the displacement of the axis of San Pedro River towards the above mentioned bank, creating an arrow-shaped sand accumulation or spit in the right side of the river mouth that is called the Punta de los Sabonenses [11]. Moreover, during the winter of 1990, there was a big storm that led to erosion in the area, which was not protected at that time, and backward shore movement of 20 meters. When the existing sewage water pipe (connected to the wastewater treatment plant) lost its foundation, it was decided that it had to be protected to avoid the serious environmental damage that would result if it broke. To reduce the reflective effect of the breakwaters walls, an experimental system of beaches placed in between detached breakwaters was designed in 1991. The loss of sand on these beaches was small but irreversible, since the grains of sand fell into the deep channel where the littoral dynamics do not bring them back. Therefore, during 1998, 2001 and 2002 periodical sand replenishment volumes between 5 to $10,000 \mathrm{~m}^{3}$ have been added to the beach; this sand came mainly from dredging the spit in the mouth of the river. No modification in the morphodynamics was noticed, mostly due to the minimal volume of sand that was involved.

The beaches studied here were regressing again in 2005 . In order to minimize the effects of erosion, the Spanish Coastal Department determined that the most suitable solution was a sand nourishment project. An environmental impact study (EIS) was not a legal requirement in this case according to the Andalusian law (July of 1994) and the Spanish law (June of 2001), due to the small quantity of sand involved $\left(20,000 \mathrm{~m}^{3}\right)$, which was far below the limit of $500,000 \mathrm{~m}^{3}$. Nevertheless, an EIS was performed by the Spanish Coastal Department "just in case."

Subsequently, the Atlantic-Andalusian Coastal Service commissioned an environmental surveillance plan (ESP) that would monitor the replenishment project. Another objective of the ESP was to establish the previous environmental measurements in order to guarantee that the instructions and specifications contained in the EIS were observed.

The first objective of this strategy is the formation of a beach with some minimal conditions of use, stability and duration. This way, not only a recreational area is gained but also protection of the coastal lands located behind the beach. For this project, it was important to remember the aforementioned episode about the almost ruined waste pipe in 1990.

\section{METHODOLOGY}

\subsection{Beach Nourishment}

Generally speaking, there are two ways to extract and dump sand onto nourished beaches. The first way is dredging sand from the seafloor using a pump that suctions fluidized sand and places it in the area to be nourished. Once the sediment is dumped, it is distributed with appropriate machines. In the second method, the sand is taken from terrestrial deposits (quarries, quaternaries dunes, marshes, etc.) by backhoes or frontal loaders and transported by trucks.

In our case, the sand was provided by a restoration project in a nearby salt marsh. Therefore, the sand has a marine origin, although the extraction process was not performed with a dredge but with a backhoe. During the unloading process, the sand piles were extended by bulldozers and redistributed by the surge depending on the size of the grain and other parameters.

\subsection{Environmental Study}

An EIS of the area in question was carried out a priori, taking into account the area located inside the Cadiz Bay Nature Reserve. This area corresponds to the part of the beach situated opposite from the La Algaida pine wood (see Fig. 1).

An ESP was then developed, based on the principle of gaining the maximum effect with a minimal effort, to protect the plant and animal species of the area; basically, the ESP was conducted in the protected area, as the rest of the area is part of an urban beach. This plan included considerations such as dampening the paths used by the construction vehicles to avoid the generation of particles in suspension (dust), controlling noises and vibrations, and indicating the pathways for trucks, machinery and dumping equipment.

Moreover, special care was taken not to leave the machinery on the beach during periods of inactivity. There were receptacles that were kept under inspection to contain accidental dumping from the machinery; these receptacles would later be removed by the appropriate manager. The speed of the trucks was controlled on the roads and it was verified that the noise level was acceptable. Furthermore, there was the Claims book where complaints coming from the local population could be registered. Finally, when the project was completed, it was verified that the waste generated by the construction was removed.

Special attention was paid to protect the most emblematic plant species, such as the Juniperus phoenicea in the nearby areas of the pine woods or the Spartina maritima (see Fig. 3) in the intertidal area; this is a habitat area of the European Fiddler crab Uca tangeri. This species of crab is not protected but, nevertheless, it enjoys a special popularity among the population due to its abundance and because it is a characteristic animal of the area (Fig. 4). Since the Uca tangeri is a popular crustacean in local gastronomy, a visual inspection was carried out where the number of burrowed holes per square meter was counted in order to compare the density of the holes before and after the nourishment project. 


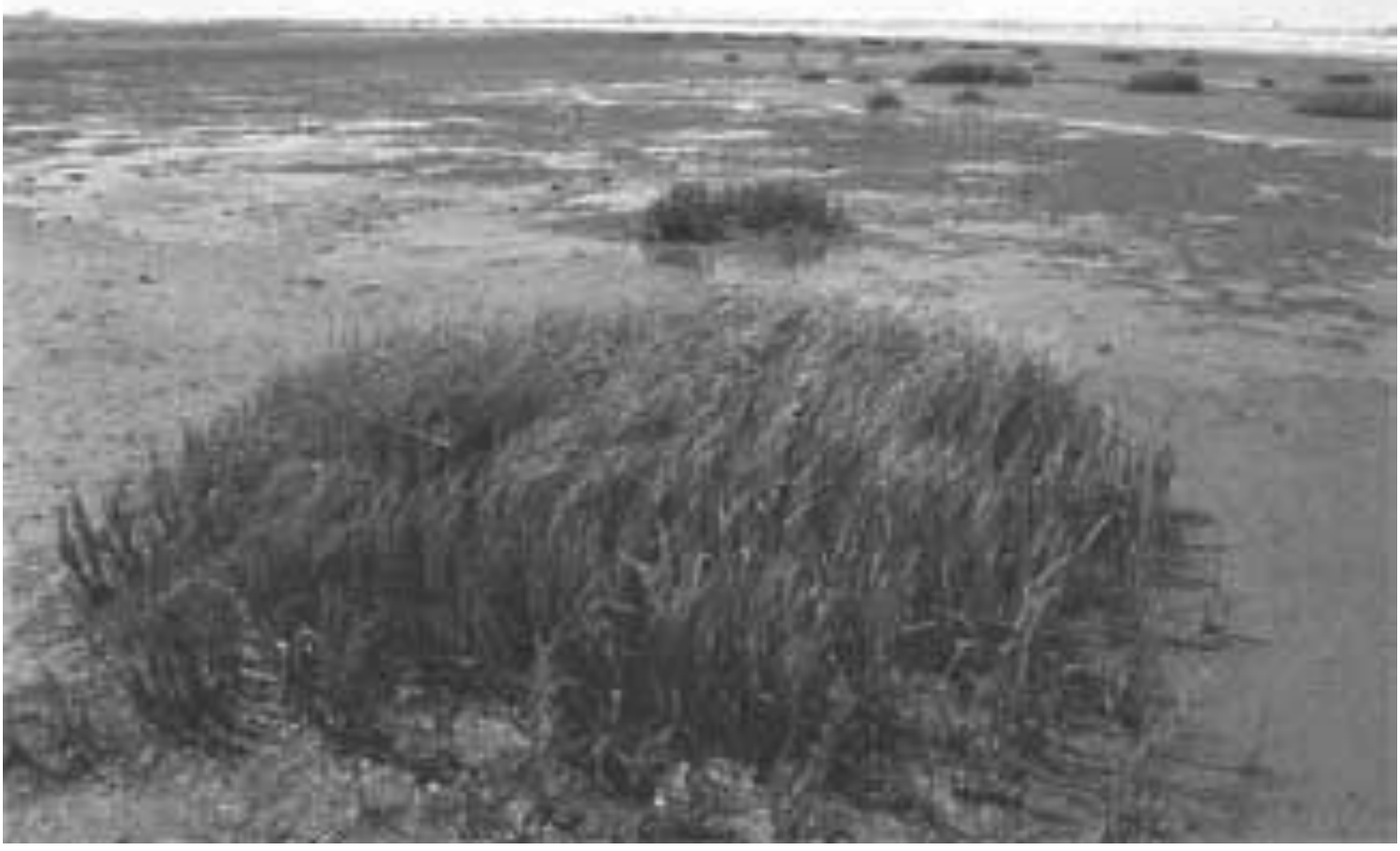

Fig. (3). Specimen of Spartina maritima, emblematic plant specie which is characteristic of the area.

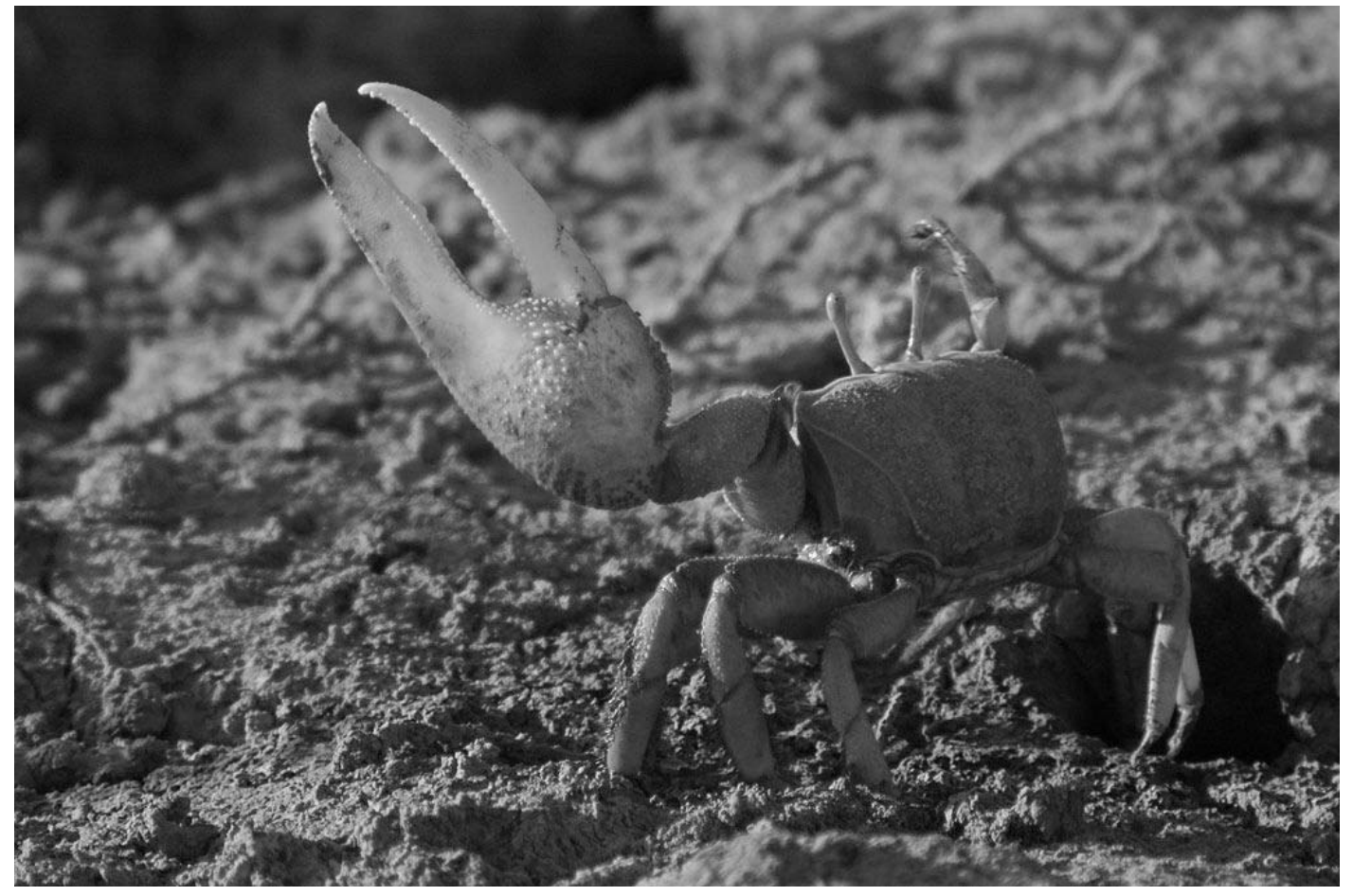

Fig. (4). Male specimen of Uca tangeri.

To introduce the reader to its living habits, we note that fiddler crabs (genus $U c a$ ) are gregarious crustaceans that inhabit tropical and temperate estuarine environments. There are more than 100 recognized species of the $U c a$ genus [12] and all of them construct burrows. Fiddler crabs are highly dependent on their burrows. They use them to hide during high tide, escape from predators [13, 14] and mate, breed and buffer physiological stresses caused by the temperature and water [15]. Studies on this genus [16] show that factors controlling the ability of crabs to make and maintain their 


\begin{tabular}{|c|c|c|c|}
\hline \multicolumn{4}{|l|}{ DATE } \\
\hline \multicolumn{4}{|l|}{ TECHNICIAN'S NAME } \\
\hline \multicolumn{4}{|l|}{ TRAMO } \\
\hline & YES & NO & COMMENTS \\
\hline $\begin{array}{l}\text { Signals in the machinery travelling zone a } \\
\text { dumping zone are correct }\end{array}$ & & & \\
\hline $\begin{array}{l}P \text { aths are been watered to avoid generatio } \\
\text { suspended particles }\end{array}$ & & & \\
\hline $\begin{array}{l}\text { During inactivity periods, is the machinery } \\
\text { the beach? }\end{array}$ & & & \\
\hline $\begin{array}{l}\text { Oil residues are reserved in cans that are } \\
\text { picked up by a trained residues manager }\end{array}$ & & & \\
\hline $\begin{array}{l}\text { There are spots in the floor. Indicate their } \\
\text { diameter. }\end{array}$ & & & \\
\hline There are "clearings" in the vegetation. & & & \\
\hline $\begin{array}{l}\text { Truck's speed passing through the paths } \\
\text { correct }\end{array}$ & & & \\
\hline The noise level is not particularly annoyin & & & \\
\hline $\begin{array}{l}\text { There are complaints in the Complaint } \\
\text { Registration Form. }\end{array}$ & & & \\
\hline $\begin{array}{l}\text { At the ending of the work, all the residues } \\
\text { have been collected. }\end{array}$ & & & \\
\hline
\end{tabular}

Fig. (5). The form filled in by the environmental technician and signed both by him and a representative of the construction contractor. The degree of observance of the Environmental Study Plan is reflected in a schematic way.

burrows affect their distribution and abundance. Thus, the burrows are essential to the lives of these animals, but they could get buried and crushed during nourishment projects. In addition, the chameleon (Chamaeleo chamaeleon) is present in the local pinewood fauna. This species is catalogued as "in danger of extinction" [17], and its habitat is protected by the Spanish law about the Conservation of Wild Flora and Fauna, which was enacted in April of 1989. To protect this species of chameleon, it was emphasized in the environmental surveillance plan that trucks must take pathways indicated by signposts and information panels when crossing through the pine wood area.

When the sand replenishment project was initiated, periodical weekly visits to the area were made in order to determine the degree of observance and establish the complementary environmental measures needed in case of unexpected problems or complaints from the local population. In addition, photographs were taken to monitor the environmental state and progress of the project. A technician from the project's administration and a representative from the construction company signed a form to ensure that the plan listed above was followed (Fig. 5). The aim of this monitoring campaign was to provide information on issues of genuine concern and produce data to evaluate the changes caused by the construction activities.
In addition, the granulometry of the poured sand was continuously analyzed and compared with that of the beach to check the compatibility between native and borrowed sand. Finally, after every visit to monitor the progress of the replenishment project, a technical report was written and sent to the administration management.

\subsection{Granulometric Analysis}

Several samples were taken before, during and after the replenishment of the three beaches (Fig. 1) and from different profiles of the beaches, although a uniform pattern was always used. Each of the samples was sieved and the corresponding granulometry was obtained.

Although the Unified Soil Classification is the standard classification used by engineers (gravel; coarse, medium and fine sand; silt; and clay), the Wentworth classification system, which is widely used by geologists, has become more widely used for designing beach fills. Wentworth size classes have limits in millimeters determined by the relation $2^{\mathrm{n}}$, where $\mathrm{n}$ is any positive or negative integer including zero. For example, the limits on the size of the sand in the Wentworth scale are 0.0625 and $2 \mathrm{~mm}$, which correspond to $2^{-4}$ and $2^{+1} \mathrm{~mm}$, respectively [3]. This property led Krumbein [18] to propose a phi unit scale based on the definition: 


$$
\mathrm{X}_{\Phi} \text { (units phi) }=-\log _{2} \mathrm{X} \text { (diameter in } \mathrm{mm} \text { ) }
$$

Since the sand size distribution of a beach is typically lognormal, a unit like phi has an advantage. The phi unit is based on the logarithm of the size so it better emphasizes the small yet significant differences between the finer particles in the distribution.

The methodology used in this study follow the recommendations for the management of dredged material in Spanish ports [19]. The accumulated fractions that go through every sieve are represented in a chart that indicates the $\mathrm{D}_{50}$ sieve size and other statistical parameters such as $\mathrm{D}_{16}$ and $\mathrm{D}_{84}$. For instance, $\mathrm{D}_{50}$ refers to the average sieve opening that would allow $50 \%$ by weight to pass through. Once these values are reconverted in $\Phi$ (phi) units they allow us to calculate their average and typical deviation. Finally, the overfill factor ratio of James [20] indicates the probable behaviour of the borrowed or new material on the beach by comparing the parameters of the native and new sediments. In this way, some criteria are established to predict the loss of the fine material that often takes place immediately following placement.

\subsection{European Fiddler Crab (Uca tangeri)}

During the course of the sand replenishment, some opposing opinions arose about the apparent damage suffered by the Uca tangeri as a consequence of the poured sand, as an ecologist organization argued that the crabs were buried and crushed by the caterpillars of the bulldozer that spread out the sand. Though some authors have stated that anthropogenic disturbances like beach nourishment have substantial effects on shore-side benthic communities [21], other researchers have demonstrated the opposite. For instance, Peterson et al. [5] documented a $100 \%$ increase in abundance of coquina clams following bulldozing activities. Therefore, in order to asses this issue, a complementary EIS of the replenished area was carried out after the bulldozing was completed in order to determine the effects of the project on the crabs. First, a study of the distribution of this species was carried out.

Next, some theoretical calculations and practical experiments were performed. It was assumed that the crabs live in $30 \mathrm{~cm}$ deep holes burrowed in the sediment [22]. The aim of the theoretical calculations was to compare the pressure exerted by the bulldozer (in low water tide) with that exerted by the column of water during the rising tide.

In order to check the validity of these calculations, some practical experiments were carried out in the laboratory. These experiments reproduced the conditions experienced by the crab as a bulldozer passes. It was necessary to capture some specimens of Uca tangeri, which were released after the experiment without suffering any damage. It is interesting to note that the Uca tangeri is the only species of fiddler crab found in Europe. The male can be easily distinguished from the female by its claw (Fig. 4) that can be up to 30 times bigger than the smaller claw [22]. The scrumptious claw fulfils two functions: on the one hand it is used as a weapon against crabs of the same sex during sexual competition, and on the other hand it is also used for winding movements to attract the female crabs.
The uca tangeri digs a hole approximately $30 \mathrm{~cm}$ deep that allows it to take shelter during high water tide and protect itself from predators. When the tide falls, the crab spends between 1 and $1.5 \mathrm{~h}$ repairing the damages to its hole caused by the high tide. The male crabs use little balls of sediment to form a sort of semicircular barrier [23], while the females place these little balls in a pile.

The laboratory experiment involved applying pressure over a $30 \mathrm{~cm}$ hole of a crab buried in the sediment contained in a receptacle of known dimensions. To avoid possible damage to the crab from miscalculations, a much smaller pressure than that calculated was applied, and the pressure was increased only after it was verified that the animal was not suffering any harm. Three increments in pressure where applied to the crabs (being the last one the pressure pursuited by the bulldozer). This experiment was replicated one more time. In addition, and to avoid distorted results produced by the stress of the crab, the individuals were periodically changed.

Once all of the necessary data was compiled, a matrix indicating the importance of the different impacts corresponding to the phases of the project's execution was prepared. The importance of a particular impact can be established using the Conesa matrix [24]. According to Conesa, impacts with values of importance below 25 are irrelevant or negligible (see Table 1). This matrix is a causeeffect type; the columns show the actions that have an impact and the environmental factors that receive the impacts arranged in rows (Tables $\mathbf{2}$ and $\mathbf{3}$ ).

Table 1. Range of Values of the Environmental Impact

\begin{tabular}{|c|c|}
\hline Values of Importance & Type of Impact \\
\hline \hline$<25$ & Irrelevant \\
\hline $25-50$ & Mild \\
\hline $50-75$ & Severe \\
\hline$>75$ & Critical \\
\hline
\end{tabular}

Table 2. Impact Matrix During Execution Phase

\begin{tabular}{|c|c|c|c|c|c|}
\hline & \multicolumn{5}{|c|}{ IMPACTING ACTIONS } \\
\hline \multirow{4}{*}{ 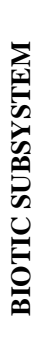 } & & & $\begin{array}{l}\text { Machinery } \\
\text { Passing }\end{array}$ & Dumping & Total \\
\hline & \multirow{2}{*}{ Fauna } & $\begin{array}{l}\text { Habitat (cleaning } \\
\text { of the way, lorries } \\
\text { passing, ...) }\end{array}$ & -19 & & -19 \\
\hline & & $\begin{array}{l}\text { Blockage of the } \\
\text { holes made by the } \\
\text { infauna }\end{array}$ & & -14 & -14 \\
\hline & Flora & Pinewood plants & -21 & & -21 \\
\hline
\end{tabular}

\section{RESULTS AND DISCUSSION}

The results of the granulometric analysis of the sand samples are shown in Table 4. 
Table 3. Impact Matrix after the Construction was Completed

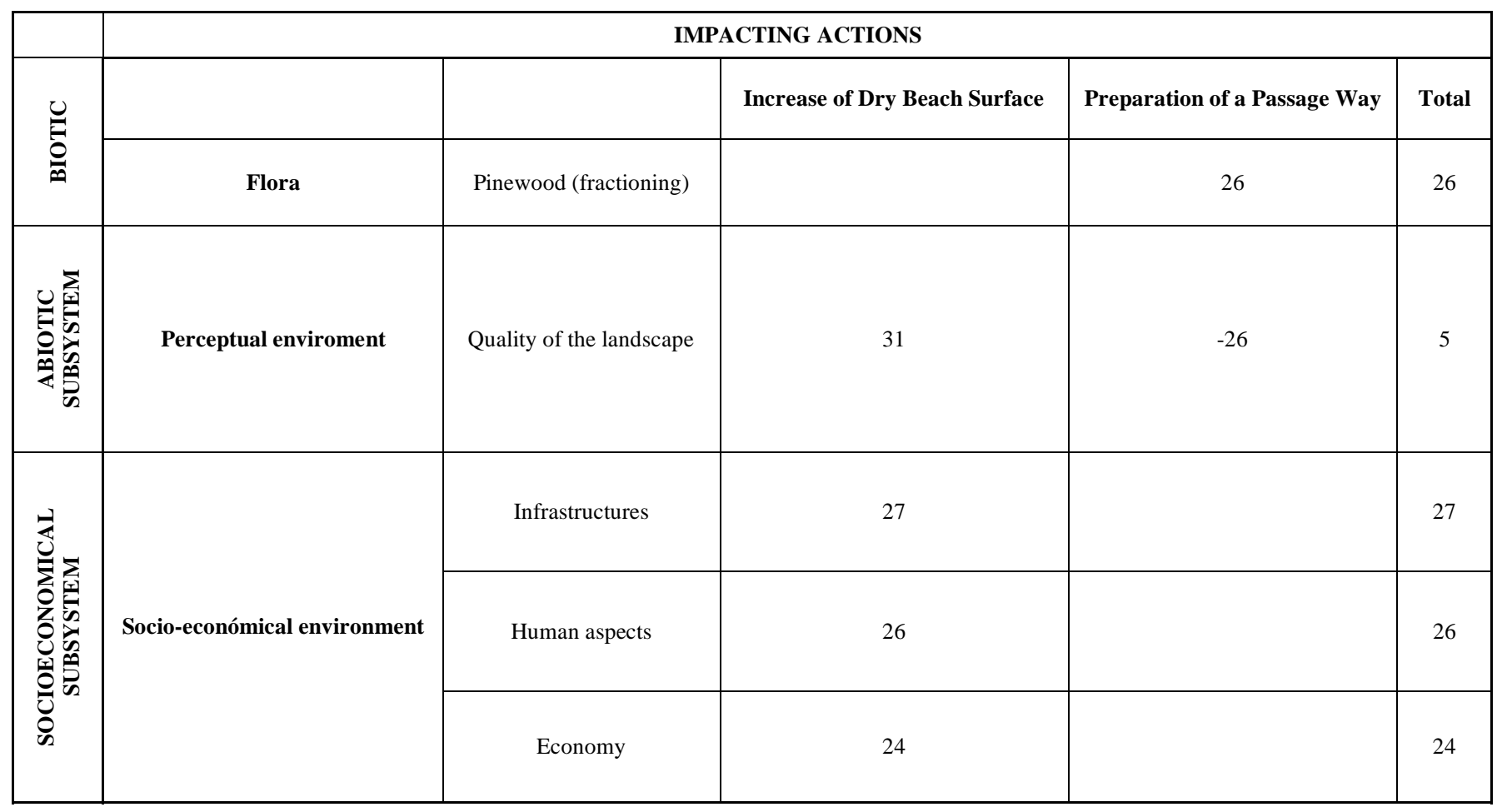

Table 4. Average Granulometric Parameters: with (ws) and without Shells (ns)

\begin{tabular}{|c|c|c|c|c|c|}
\hline ZONE & & D50 ws & D50 ns & Silt ws & Silt ns \\
\hline \multirow{3}{*}{$\mathbf{A}$} & Before & 0.24 & 0.23 & 0.06 & 0.08 \\
\hline & After & 0.2 & 0.2 & 1.29 & 1.30 \\
\hline & Difference & $-0,04$ & $-0,03$ & 1.23 & 1.22 \\
\hline B & Difference & $+0,03$ & $+0,03$ & 0.38 & 0.64 \\
\hline \multirow{3}{*}{$\mathbf{C}$} & Before & 0.29 & 0.24 & 0.00 & 0.06 \\
\hline & After & 0.2 & 0.19 & 1.13 & 1.09 \\
\hline & Difference & $-0,09$ & $-0,05$ & 1.13 & 1.03 \\
\hline
\end{tabular}

The resulting sand after the beach was replenished had some finer grains (silt) than the original sand, but the proportion of this finer sand was never higher than $1.5 \%$, which is a negligible amount and was washed away in a few days [25]. Moreover, the new sand has a slightly bigger size than the original sand at Caño de Cortadura beach $(+0.03 \mathrm{~mm}$ in zone B). On the other hand, the new sand is slightly smaller not only at pinewood beach $(-0.04 \mathrm{~mm}$ in zone A) but also at the breakwaters beach $(-0.09 \mathrm{~mm}$ in zone C). It is noteworthy that a difference of $0.1 \mathrm{~mm}$ in the sizes of the new and old sands is an acceptable limit according to USACE [26] or Galofre et al. [27].
Regrettably, sand with bigger grain sizes was not found in the surrounding area. Therefore, the rate of erosion of this new sand will be similar to the previous rate of erosion, which was about 4,000 $\mathrm{m}^{3} /$ year [28].

A noticeable increase in the density of crab holes was found after the sand replenishment. It is natural to assume that this increase was not a consequence of the construction project, but that it follows the biological rhythm of the animals, since, as the summer gets closer, the number of holes per square meter increases [5]. Furthermore, it was found out from the study of the distribution of Uca tangeri population that, according to the calculations of the 


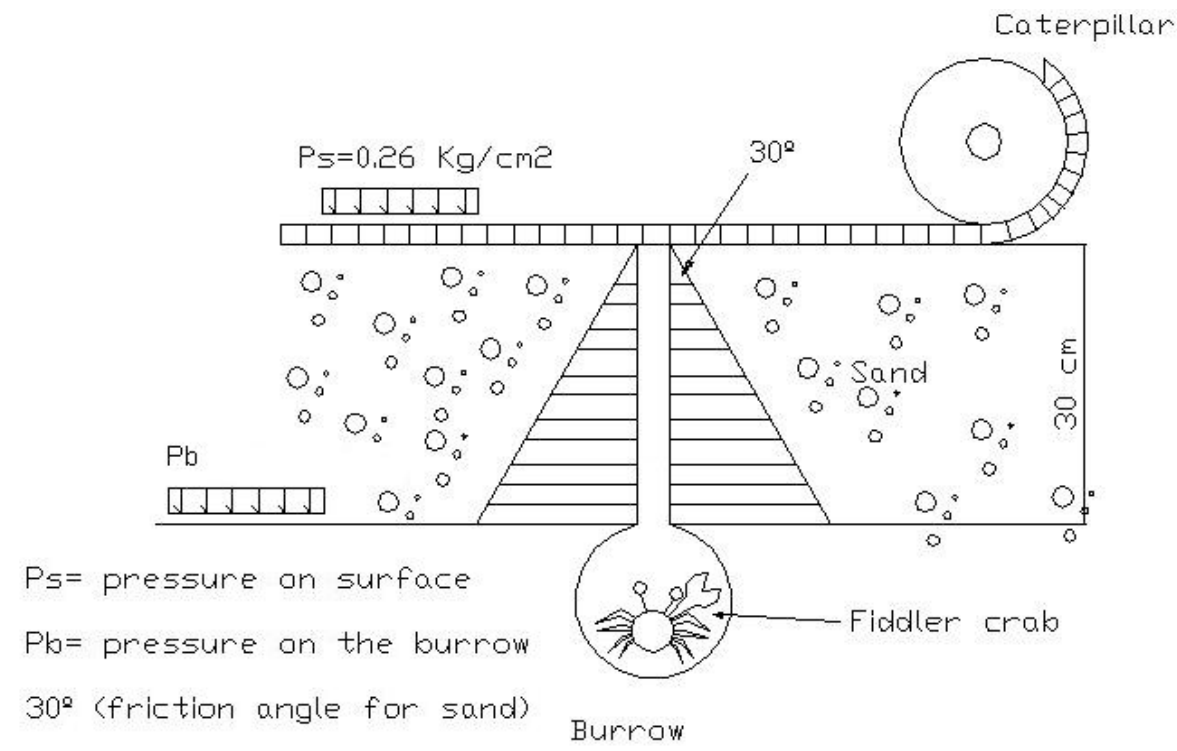

Fig. (6). The pressure over the burrow walls diminishes according to the internal friction angle of the sand. The fiddler crab only support the tidal water level pressure.

correlation rates, there was a relation between the Uca tangeri and a plant species. Virtually the entire fiddler crab population of San Pedro is associated to the vicinity of Spartina Maritima (Fig. 3), over which no sand was poured at any time.

Experiments in the laboratory were carried out in order to compare the pressure exerted by the bulldozer passing over the crab burrows (during low tide) to that exerted by the column of water during rising tides. The results indicate that the pressure produced by the column of water $\left(0.4 \mathrm{Kg} / \mathrm{cm}^{2}\right)$ during high water tide over a crab who lives buried at $30 \mathrm{~cm}$ deep is greater than the pressure experienced by the same crab during low tide as a bulldozer passes overhead. A bulldozer with two $3 \mathrm{~m}$ long by $0.5 \mathrm{~m}$ wide caterpillars and a weight of $8,000 \mathrm{~kg}$ was used to spread out the sand. This means that there was a pressure of $0.26 \mathrm{~kg} / \mathrm{cm}^{2}$ on the surface of the sand. As the crab hides into his burrow, which

Table 5. A Methodology for the Determination of the Environmental Impact (Adapted from V. conesa (1995))

\begin{tabular}{|c|c|c|}
\hline $\begin{array}{cl}\text { NATURE } & \\
\bullet & \text { Beneficious impact } \\
\bullet & \text { Damaging impact }\end{array}$ & $\begin{array}{cll}\text { INTENSITY(I) } & \\
\bullet & \text { Low } & 1 \\
: & \text { Medium } & 2 \\
\bullet & \text { High } & 3 \\
: & \text { Very high } & 4 \\
\bullet & \text { Total } & 5 \\
\end{array}$ & \\
\hline 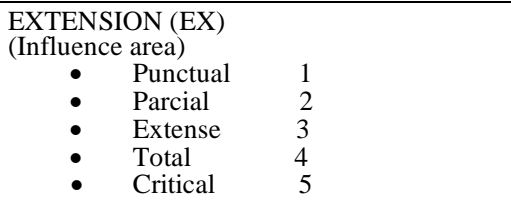 & $\begin{array}{c}\text { TERM (TE) } \\
\text { (Term of manifestation) } \\
\bullet \quad \text { Long term } \\
-\quad \text { Medium term } \\
-\quad \text { Short term } \\
\quad \text { Critical }\end{array}$ & $\begin{array}{l}1 \\
2 \\
3 \\
4\end{array}$ \\
\hline 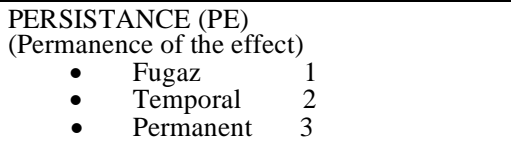 & $\begin{aligned} & \text { REVERSIBILITY (RV) } \\
& \\
& \text { - } \text { Short term } \\
& \text { Medium term } \\
& \text { Critical }\end{aligned}$ & $\begin{array}{l}1 \\
2 \\
3\end{array}$ \\
\hline $\begin{array}{ll}\text { SINERGY (SI) } & \\
\text { (Periodicity of manifestation) } & \\
\text { - Without sinergism (simple) } & 1 \\
\text { - Sinergia } & 2 \\
\text { - Very sinergic } & 3\end{array}$ & $\begin{array}{l}\text { ACUMULATION (AC) } \\
\text { (Progresive increment) } \\
\qquad \quad \text { Simple } \\
\bullet \quad \text { Acumulative }\end{array}$ & $\begin{array}{l}1 \\
2\end{array}$ \\
\hline $\begin{array}{c}\text { EFFECT (EF) } \\
\text { (relation cause-effect) } \\
\qquad \quad \text { Indirect } \\
-\quad \text { Direct }\end{array}$ & $\begin{array}{c}\text { PERIODICITY (PR) } \\
\text { - } \quad \text { Non periodica } \\
\text { - } \quad \text { Periodical } \\
\text { Continuous }\end{array}$ & $\begin{array}{ll} & \\
\text { iscontinuous } & 1 \\
& 2 \\
& 3\end{array}$ \\
\hline 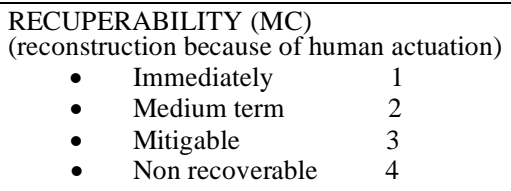 & 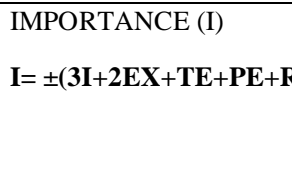 & $\mathrm{SI}+\mathrm{AC}+\mathrm{EF}+\mathrm{PR}+\mathrm{MC})$ \\
\hline
\end{tabular}


is $30 \mathrm{~cm}$ deep, the pressure on the burrow walls diminishes according to the internal friction angle of the sand (Fig. 6). Therefore, the sand replenishment project could have been carried out with a bulldozer that weighted 4 times greater than the one used without endangering the Uca tangeri.

Furthermore, Peterson et al. [5] have attributed the reduction of the densities of crabs and other organisms to the difference in sand size for similar projects. Consequently, it can be assumed that the negative impact of beach bulldozing nourishment was presumably not as large for this particular beach nourishment project.

The second environmental impact study included constructing matrices of importance corresponding to the nourishment and posteriori phases in order to obtain the global impacts of the project. During the nourishment phase, the total impact had a negative value that was less than 25 in the matrix (Table 2), which means that the environmental impact was negative but negligible. Once the project was finished the total environmental impact was slightly higher than 25 but it had a positive sign (Tables $\mathbf{3}$ and $\mathbf{5}$ ).

\section{CONCLUSIONS}

A methodology for estimating the environmental impact on a beach of a sand replenishment project is presented in this paper. The environmental parameters established in the Spanish Regulations for the Evaluation of Environmental Impact were assessed. During the execution phase, the total impact took a negative value, but the impact was reversible and compatible with the environment. During the functioning phase, the total environmental impact was small as well but of a positive sign.

Some improvements to the beach were made from socioeconomical and environmental points of view: the recreational value of the beach was increase, and the pinewood area behind the beach was better protected after the project's completion, which is partially the result of the preparation of an entrance path to the beach that avoids passing through the pinewood.

This study also focused on the impact of the sand replenishment project on the Uca tangeri (fiddler crab) population. We concluded that the result was a negative but negligible impact. In addition, there were no changes to the sand's density, grain size and color (the slope of the beach was visibly increased but only for a short period). The new sand was taken from a nearby salt marsh, and the great similarity between the two types of sand likely helped reduce negative effects on the Uca Tangeri. Furthermore, from the experiments and calculations it was concluded that the crabs bear more pressure during high tide than when the bulldozers passed overhead.

As for the littoral dynamics, we do not think that they will be altered, because the volume of newly added sand is relatively small. Moreover, the volume of sand involved in this project is similar to other operations that have already been completed without problems of any sort.

Finally, since the long-term data on the natural fluctuation in the presence and abundance of populations of marine organisms (due to storm waves, winter mortality, etc.) are often not available, an assessment of the effects of sand nourishment projects is difficult to complete in most cases. Nevertheless, monitoring campaigns and evaluations of the environmental impact of beach nourishment and scraping projects must be carried out not only during construction but also after the project has been completed. These kinds of studies are the only way to obtain data that can be useful for creating measures to diminish the environmental impact of replenishment activities in the future.

\section{ACKNOWLEDGEMENTS}

The authors would like to thank the Spanish Coastal Department and the Ministry of Environment for allowing us to easily access useful data.

\section{REFERENCES}

[1] Green K. Beach nourishment: a review of the biological and physical impacts. Atlantic States Marine Fisheries Comission: Washington 2002.

[2] Pilkey O, Wright HL. III Seawalls versus beaches. J Coast Res 1988; 4: 41-64.

[3] CERC. Shore Protection Manual. Army Eng Corps. Vicksburg 1984.

[4] Nelson DA, Pullen EJ. Environmental considerations in using beach nourishment for erosion protection, in Proc. of the $2^{\text {nd }}$ Water Quality and Wetlands Management Conference, New Orleans. 1985.

[5] Peterson CH, Hickerson DH, Johnson GG. Short-Term consequences of nourishment and bulldozing on the dominant large invertebrates of a sandy beach. J Coast Res 2000; 16: 368-38.

[6] Rumbold DG, Davis PW, Peretta C. Estimating the effect of beach nourishment on caretta caretta (Loggerhead Sea Turtle) Nesting. Restor Ecol 2001; 9: 304-10.

[7] Stauble DK, Nelson WG. Guidelines for beach nourishment: a necessity for project management. ASCE, Coastal Zone'85. Baltimore 1985.

[8] Adriaanse LA, Coosen J. Beach and dune nourishment and environmental aspects. Coast Eng 1991; 16: 129-46.

[9] Muñoz-Perez JJ, Gomez-Pina G, Enriquez J. Comments on 'An approximation to short-term evolution and sediment transport pathways along the littoral of Cadiz Bay (SW Spain)' by Anfuso and others [Environm Geol 56:69-79]. Environ Earth Sci 2009, 59(2), 477-479.

[10] Muñoz-Perez JJ, de la Casa A, Enriquez J. Erosion in the mouth of the river San Pedro (Cadiz): Proposal and study problematic of solutions. Civil Eng 2001; 123: 71-81.

[11] Muñoz-Perez JJ, Abarca JM. Influence of the wind and the variations of the atmospheric pressure in the level of the sea of salt marshes and estuaries. Ciencias Marinas 2009; 3505: 21-32.

[12] Rosenberg MS. The systematics and taxonomy of fiddler crabs: a phylogeny of the genus Uca. J Crust Biol 2001; 21(3): 839-69.

[13] Frix MS, Hostetler ME, Bildstein KL. Intra- and interspecies differences in responses of Atlantic sand (Uca pugilator) and Atlantic marsh (U. pugnax) fiddler crabs to simulated avian predators. J Crust Biol 1991; 11(4): 523-9.

[14] de la Iglesia HO, Rodriguez EM, Dezi RE. Burrow plugging in the crab Uca Uruguayensis and its synchronization with photoperiod and tides. Physiol Behav 1994; 55: 913-9.

[15] Crane J. Fiddler crabs on the world Ocypodidae: Genus Uca. Princeton, New Jersey: Princeton University Press 1975; pp. 736.

[16] Bertness MD, Miller T. The distribution and dynamics of Uca pugnax burrows in a New England salt marsh. J Exp Mar Biol Ecol 1984; 83: 211-37.

[17] ICONA, Red book of Vertebrates of Spain, 1992. 
[18] Krumbein WC. Application of logarithmic moments to size frequency distribution of sediments. J Sediment Petrol 1936; 6(1): 35-47.

[19] CEDEX. Recommendations for the management of dredged material in the Spanish ports. Ministry of Public Works, Madrid, 1994.

[20] Muñoz-Perez JJ, JM Abarca. 'Influencia del viento y de las variaciones de la presión atmosférica en el nivel del mar de marismas y estuarios'. Rev Obras Publicas 2009; 3505: 21-32.

[21] Bilodeau AL, Bourgeois RP. Impact of beach restoration on the deep-burrowing ghost shrimp, Callichirus islagrande. J Crust Biol 2004; 20(3): 931-6.

[22] Ribeiro $P$, Iribarne $O$, Daleo $P$. The relative importance of substratum characteristics and recruitment in determining the spatial distribution of the fiddler crab. J Exp Mar Biol Ecol 2005, 314: 99-111.
[23] Burford F, McGregor P, Oliveira R. Response of fiddler crab (Uca tangeri) to video playback in the field. Acta Ethol 2000; 3: 55-9.

[24] Pilkey O, Wright HL III, Seawalls versus Beaches. J Coast Res 1988; SI 4: 41-64.

[25] Gomez-Pina G, Fages L, Ramirez JL, Enriquez J, Muñoz-Perez JJ. A critical review of beach restoration projects in the northern coast of Cadiz (Spain) after thirteen years. Proceedings of the International Conference on Coastal Engineering, San Diego, California 2007; pp. 4167-4178.

[26] USACE (US Army Corps of Engineers). Environmental Engineering for Coastal Protection 1989; EM 1110-2-1204: 1-4.

[27] Galofre J, Montoya F, Medina R. Compatibility of borrow material for beach fills: a revised formulation. Coastal Dynamics'01, Lund (Sweden), June 2001.

[28] Muñoz-Perez JJ, Lopez B, Gutierrez-Mas JM, Moreno L, Cuena GJ. Cost of beach maintenance in the Gulf of Cadiz (SW, Spain). Coast Eng 2001; 42: 143-53.

(C) Herrera et al.; Licensee Bentham Open.

This is an open access article licensed under the terms of the Creative Commons Attribution Non-Commercial License (http://creativecommons.org/licenses/by$\mathrm{nc} / 3.0 /$ ), which permits unrestricted, non-commercial use, distribution and reproduction in any medium, provided the work is properly cited. 